\section{SOBRE O QUALIS DE PERIÓDICOS DA CAPES}

Nising a sua página Classificação da produção intelectual, a Capes define o QualisPeriódicos como "um sistema usado para classificar a produção científica dos programas de pós-graduação no que se refere aos artigos publicados em periódicos científicos" (Capes, 2016). E oferece sua breve descrição, a partir de três questões: $O$ que é? Quem faz e como é feita a classificação? Prá que serve?

$\mathrm{O}$ trecho negritado, no original, remete à função precípua do sistema e ao campo de coleta das variáveis classificatórias: avaliação dos programas de pós-graduação, nas diversas áreas do conhecimento, pela Capes. A classificação dos periódicos é realizada por Comitês de consultores, conforme critérios definidos por cada área e aprovados pelo Conselho Técnico Científico da Educação Superior (CTC-ES), passando por um processo anual de atualização. Os periódicos podem ser classificados nos estratos de A1, o mais elevado; A2; B1; B2; B3; B4; B5; até C.

A partir de 2015, a classificação dos periódicos é organizada através do módulo Qualis da Plataforma Sucupira, que coleta dados para avaliação dos programas de pós-graduação recomendados pela Capes. Nesse contexto, a publicação de artigos pelos pesquisadores vinculados à pós-graduação é o que traz os títulos de periódicos para o campo de coleta do Qualis: então, quanto mais próximo da área estiver o periódico maior será a relevância da produção, para autores e periódicos. Desse modo também se facilita a vida do leitor, como sabiamente propôs Ranganathan, contribuindo para aumentar a consistência da literatura nos respectivos campos científicos.

A última avaliação dos periódicos pelo Qualis tomou como base o ano de 2015 e na área da Ciência da Informação, dentre 42 periódicos, foram classificados três no estrato A1 (Perspectivas em Ciência da Informação, Informação \& Sociedade e Transinformação); três no estrato A2 (Em Questão, Encontros Bibli e Informação \& Informação); 14 periódicos no estrato B1; três no estrato B2; quatro no estrato B3; um periódico no estrato B4; 12 no estrato B5; e dois no estrato $C$ (periódicos considerados não científicos). ${ }^{1}$

Nesse contexto, os editores científicos do campo da Ciência da Informação podem trabalhar de forma colaborativa com os programas de pósgraduação, no sentido de ampliar o espaço para publicação de artigos, ao mesmo tempo em que promovem a indexação dos periódicos nas bases de dados exigidas pelo estrato B1 - LATINDEX (Sistema Regional de Información em Línea para Revistas Científicas de América Latina, el Caribe, España e Portugal); REDALYC (Red de Revistas Científicas de América Latina, el Caribe, España y Portugal); DOAJ (Directory of Open Access Journals - periódicos eletrônicos); CLACSO (Consejo Latinoamericano de Ciências Sociales); CLASE (Citas Latinoamericanas em Ciencias Sociales y Humanidades).

Os critérios para a área de Comunicação e Informação estão disponíveis no documento Considerações sobre Qualis Periódicos, de 2016, e uma leitura atenta por pesquisadores e editores certamente acarretará benefícios para ambos e, por extensão, para a Ciência da Informação, traduzindo-se em publicações periódicas que representem a pujança da dinâmica da pesquisa, nos programas de pós-graduação da área.

\section{Gustavo Henrique de Araújo Freire} Isa Maria Freire

Editores

I Conforme Carvalho (2017). Disponível em http://biblioo.cartacapital. com.br/saiba-o-que-e-qualis-capes/. Para relação e links dos periódicos brasileiros da área ver: http://www.lti.pro.br/?Revistas_Brasileiras_em CI. 


\section{REFERÊNCIAS}

CAPES. Classificação da produção intelectual. Qualis periódicos. Publicado em 01/08/2016. Disponível em: http://www.capes.gov.br/ avaliacao/instrumentos-de-apoio/classificacaoda-producao-intelectual. Acesso em 11/12/2017.

CAPES. Considerações sobre Qualis Periódicos. Área Ciências Sociais Aplicadas 1 (atual Comunicação e Informação). 2016. Disponível em: http://capes.gov.br/images/ documentos/Qualis_periodicos_2016/qualis_ comunicacaoeinformacao.pdf. Acesso em 11/12/2017.

CARVALHO, Jonathas. Saiba o que é Qualis Capes e quais os periódicos da CI com essa classificação. biblioo cultura informacional. Publicado em 03/03/2017. Disponível em: http:/ / biblioo.cartacapital.com.br/saiba-o-que-equalis-capes/. Acesso em 11/12/2017. 